\title{
Volatile organic compounds of pyroligneous liquor of bamboo sprout produced in damyang-gun
}

\author{
Eunsil Lee ${ }^{1}$, Hyejin Jang ${ }^{1}$, Songjin $\mathrm{Lee}^{2}$ and Jaeho Ha ${ }^{1, \star}$ \\ ${ }^{l}$ Food Analysis Center, Korea Food Research Institute \\ ${ }^{2}$ Bamboo Resource Research Institute, Damyang-gun, Jeollanamdo
}

(Received June 4, 2013; Revised August 2, 2013; Accepted August 2, 2013)

\section{담양군 죽초액의 휘발성성분 분석 \\ 이은실 ${ }^{1} \cdot$ 장혜진 $^{1} \cdot$ 이송진 $^{2} \cdot$ 하재호 ${ }^{1} \star{ }^{4}$ \\ 1한국식품연구원 식품분석센터, ${ }^{2}$ 담양군 대나무자원연구소}

(2013. 6. 4. 접수, 2013. 8. 2. 수정, 2013. 8. 2. 승인)

\begin{abstract}
Pyroligneous liquor as a byproduct from charcoal production of bamboo sprout produced damyanggun has the broad benefits such as improvement of soil quality, plant growth control and is mainly used for the treatment of atopic dermatitis, fungi and many other skin diseases. In this study, flavor compounds of pyroligneous liquor from bamboo sprout produced in Damyang-gun were analyzed and compared using three different methods including direct analysis (DA), headspace solid phase microextraction (HS-SPME) and stir bar sorptive extraction (SBSE). Simultaneously, the analytical conditions of GC-MS for the determination of volatile compounds were optimized. Based on volatile organic compounds detected by GCMS, SBSE and SPME methods showed higher sensitivity than direct analysis. Major compounds of pyroligneous liquor were cresol, guaiacol, $p$-ethyl guaiacol and syringol. These phenolic compounds are reported as the useful chemicals with medicinal activity.

요 약: 죽초액은 대나무 숯 제조시 발생하는 강한 산성을 가진 부산물로 $80-90 \%$ 의 수분과 200 종 이 상의 유기화합물로 구성되어 있으며, 일반적으로 토양 질 개선, 식물 생육 조절, 아토피 피부염 개선 및 항균효과 등 피부관련 질환에 널리 활용되고 있다. 본 연구에서는 담양군에서 제조한 죽초액 휘발성성 분을 direct analysis(DA)법, head space solid phase microextraction(HS-SPME)법, stir bar sorptive extraction (SBSE)법을 이용하여 GC/MS로 분리하고 동정하였다. 위 세 가지 방법을 이용하여 103 종의 화합물을 검출하였으며, HS-SPME와 SBSE방법에서 페놀류 화합물의 선택적 분석이 가능하였다. 죽초 액의 주요한 화합물은 유효한 생리활성 물질로 알려진 cresol, guaiacol, $p$-ethyl guaiacol, syringol이 분 석되었다.
\end{abstract}

Key words: Bamboo-pyroligneous liquor, volatile compounds, SPME, SBSE

Corresponding author

Phone : +82-(0)31-780-9127 Fax : +82-(0)31-780-9280

E-mail : jhkfri@gmail.com 


\section{1. 서 론}

대나무는 오래 전부터 천연약재로 사용되어 왔으며, 혈중 콜레스테롤 및 지질 조절과 항산화 효과 등 여 러 장점들 때문에 대체 작물로서 주목을 받아왔다. 우 리나라에 분포하고 있는 대나무는 전라남도 담양지방 에 $60 \%$ 이상이 집중 분포되어 있고 그밖에 경남, 충남, 강원도 등에 산재되어 있으며 그 종류가 약 50 종에 달하는 것으로 보고되고 있다. ${ }^{1}$ 대나무로부터 제조한 죽초액은 종자식물의 발아 및 유근(幼根)의 성장을 강 하게 저해하는 것으로 알려져 있을 뿐만 아니라 항균, 항산화제 역할을 하는 것으로 보고되고 있다.,3 죽초 액은 숫을 제조하는 과정에서 발생하는 연기로부터 채취되고 초산을 주성분으로 하는 강한 산성 $(\mathrm{pH} 3)$ 의 액체이며, 80-90\%의 수분과, 200 종 이상의 유기화합 물로 구성되어 있다. ${ }^{45}$ 사용목적에 따라 다른 제법으 로 만들어지고 있으며 초산의 신맛과 더불어 고유의 탄내를 가지고 있다. 현재 국내에서 생산되는 죽초액 의 대부분은 농업분야에서 친환경적으로 식물의 생장 을 조절하고 토양의 품질을 개선시키는 용도로 사용 되고 있다. ${ }^{67}$ 또한, 죽초액에는 다량의 유기산뿐만 아니 라 phenolic compounds를 함유하고 있어 피부표면에 기생하는 바이러스, 곰팡이 균의 살균작용이 뛰어나며 여드름, 노인성 건성 피부염, 만성 습진과 옴 등의 피부 질환에 효과가 탁월한 것으로 밝혀졌다. ${ }^{8-10}$

죽초액의 유효한 기능적인 성질에도 불구하고 현재 국내에서는 농약과 살충제, 퇴비 역할로서 사용이 국 한되어 왔다. 본 연구에서는 국내 대나무 자원을 이용 한 죽초액 중의 향기성분을 다양한 전처리 방법으로 분석하여 죽초액의 기능성 성분 기초 연구 및 이를 이 용한 제품개발에 대한 기초자료를 제시하고자 하였다.

\section{2. 재료 및 방법}

\section{1. 재료}

본 연구에서 사용한 죽초액 시료는 담양군에서 제공받아 $4{ }^{\circ} \mathrm{C}$ 에서 냉장 보관하여 사용하였다. 죽초액 시료는 전처리 과정에서 증류수에 20 배 희석하여 사 용하였다.

\section{2. 실험방법}

2.2.1. Direct analysis (DA)

증류수에 20 배 희석한 죽초액 $1 \mu \mathrm{L}$ 를 $\mathrm{GC} / \mathrm{MS}$ 주 입구에 주입하여 분석하였다.
2.2.2. Headspace-Solid phase microextraction (HSSPME)

HS-SPME를 위한 SPME holder 및 코팅 fiber는 Supelco (Bellefonte, PA, USA)제품을 사용하였다. 죽 초액의 향기성분 분석은 polydimethylsiloxane (PDMS) fiber $(50 / 30 \mu \mathrm{m} \mathrm{DVB} / \mathrm{CAR} / \mathrm{PDMS})$ 를 사용하였으며 fiber는 $240{ }^{\circ} \mathrm{C}$ 에서 건조시켜 불순물을 제거한 후 사 용하였다. 증류수로 20 배 희석한 죽초액 $20 \mathrm{~mL}$ 를 headspace glass vial $(20 \mathrm{~mL})$ 에 넣고 polytetrafluoroethylene (PTFE) 재질의 septum cap으로 밀폐시킨 후 Gerstel twister (Twister, Gerstel, Mullheim a/d Ruhr, Germany)에 올려 놓은 후 상온에서 $450 \mathrm{rpm}$ 의 속도로 1 시간 동안 magnetic stir bar를 회전시켜 휘발성 향 기성분을 fiber에 흡착시켰다. 흡착이 완료된 SPME fiber는 즉시 $\mathrm{GC} / \mathrm{MS}$ 주입구에 꽂아 $240{ }^{\circ} \mathrm{C}$ 에서 1 분 간 열 탈착하여 분석하였다.

\subsubsection{Stir Bar Sorptive Extraction (SBSE)}

SBSE를 위한 magnetic stir bar는 Gerstel (Mullheim a/ d Ruhr, Germany) 제품을 사용하였다. Sample을 추출하 기 전 magnetic stir bar (PDMS, $0.5 \mathrm{~mm}$ film thickness, $10 \mathrm{~mm}$ length $24 \mu \mathrm{L}$, Gerstel, Mullheim a/d Ruhr, Germany)를 $250{ }^{\circ} \mathrm{C}$ 에서 30 분간 질소 가스로 건조시켰 다. 증류수에 20 배 희석한 죽초액 $20 \mathrm{~mL}$ 를 취해 glass vial에 넣고 PDMS로 coating된 magnetic stir bar 를 넣은 후 screw cap (silicone layer/PTFE lamination, Gerstel, Mullheim a/d Ruhr, Germany)으로 막아주었 다. Sample vial을 Gerstel twister (Twister, Gerstel, Mullheim a/d Ruhr, Germany)에 올려 놓은 후 상온에 서 $450 \mathrm{rpm}$ 속도로 1 시간동안 magnetic stir bar를 회 전시켜 휘발성 향기성분을 흡착시켰다. 흡착이 완료된 stir bar는 straight tube (GC liner)에 넣어 sampler (Gerstel, Mullheim a/d Ruhr, Germany)에 장착시켰다. Stir bar는 on-line Gerstel thermal desorption unit (TDU) 에서 열로 탈착시킨 후 cooled injection system (CIS) 에서 액화질소로 응축시켰다. 이후 $12{ }^{\circ} \mathrm{C} / \mathrm{min}$ 으로 온 도를 $250{ }^{\circ} \mathrm{C}$ 까지 올려 $\mathrm{GC}$ 주입구에 주입하였다. $\mathrm{TDU}$ 온도 program은 초기온도 $40{ }^{\circ} \mathrm{C}$ 에서 $0.2 \mathrm{~min}$ 정치한 후 $600{ }^{\circ} \mathrm{C} / \mathrm{min}$ 속도로 $260{ }^{\circ} \mathrm{C}$ 까지 승온하여 $2 \mathrm{~min}$ 정 치하며 magnetic stir bar에 흡착된 향기성분을 탈착한 후 $\mathrm{TDU}$ 온도를 $40{ }^{\circ} \mathrm{C}$ 로 내렸다. 그 후 $\mathrm{CIS}$ 온도 program을 초기온도 $20{ }^{\circ} \mathrm{C}$ 에서 $0.2 \mathrm{~min}$ 정치한 후 $12{ }^{\circ} \mathrm{C} / \mathrm{min}$ 속도로 $250{ }^{\circ} \mathrm{C}$ 까지 승온하여 $\mathrm{GC}$ 주입구에 주입하였다. 
Table 1. Relative percentage quantities of the compounds identified by GC/MS in Pyroligneous liquor

\begin{tabular}{|c|c|c|c|c|c|c|c|c|c|c|}
\hline \multirow{3}{*}{$\begin{array}{c}\text { Peak } \\
\text { No. }\end{array}$} & \multirow{3}{*}{ R.T. } & \multirow{3}{*}{ Compounds } & \multirow{3}{*}{$\mathrm{KI}^{*}$} & \multirow{3}{*}{ Similarity } & \multicolumn{6}{|c|}{ Relative percentage quantities } \\
\hline & & & & & \multicolumn{2}{|c|}{ DA } & \multicolumn{2}{|c|}{ SPME } & \multicolumn{2}{|c|}{ SBSE } \\
\hline & & & & & Area \% & RSD & Area \% & RSD & Area \% & RSD \\
\hline \multicolumn{11}{|c|}{ Phenol } \\
\hline 19 & 6.09 & $p$-Xylene & & 95 & - & - & - & - & 0.01 & 18.64 \\
\hline 30 & 10.46 & Phenol & & 94 & 7.98 & 8.88 & 7.03 & 2.99 & 4.78 & 7.63 \\
\hline 35 & 11.48 & $\begin{array}{l}\text { 1-methoxy-4-methyl benzene } \\
\text { ( } p \text {-methyl anisol) }\end{array}$ & 1023 & 90 & - & - & - & - & 0.05 & 21.26 \\
\hline 39 & 12.80 & 2-Methyl phenol (o-Cresol) & 1060 & 96 & 1.71 & 15.61 & 3.82 & 3.17 & 3.69 & 8.68 \\
\hline 41 & 13.50 & $p$-Cresol/m-Cresol (isomer) & 1082 & 96 & 6.47 & 12.44 & 6.49 & 3.43 & 4.62 & 10.65 \\
\hline 42 & 13.87 & $o$-Guaiacol & 1094 & 97 & 4.95 & 8.20 & 7.62 & 2.44 & 11.50 & 8.56 \\
\hline 43 & 14.36 & 2,6-Xylenol & 1110 & 97 & - & - & 0.79 & 3.51 & 1.34 & 5.40 \\
\hline 46 & 15.39 & $o$-Ethyl phenol (Florol) & 1142 & 95 & 0.09 & 12.88 & 0.86 & 4.30 & 0.91 & 6.01 \\
\hline 47 & 15.70 & 2,4-Xylenol & 1152 & 97 & 0.44 & 18.90 & 3.20 & 4.16 & 3.25 & 4.83 \\
\hline 49 & 16.31 & $p$-Ethyl phenol & 1172 & 97 & 2.05 & 8.44 & 10.76 & 2.96 & 10.52 & 1.63 \\
\hline 50 & 16.36 & $m$-Ethyl phenol & 1173 & 95 & - & - & 0.78 & 8.50 & - & - \\
\hline 51 & 16.57 & 3-Methyl guaiacol & 1180 & 70 & - & - & 1.02 & 5.64 & - & - \\
\hline 52 & 16.76 & 6-Ethyl-m-cresol & 1186 & 91 & - & - & 0.13 & 13.43 & - & - \\
\hline 53 & 16.79 & 6-Methoxy- $m$-cresol & 1187 & 94 & - & - & 0.54 & 4.55 & 0.95 & 10.17 \\
\hline 54 & 17.02 & 2-Methoxy-p-cresol & 1194 & 93 & 2.29 & 9.38 & 5.47 & 2.52 & 8.12 & 2.63 \\
\hline 55 & 17.25 & 1,2-Benzenediol (Pyrocatecol) & 1202 & 94 & 4.31 & 18.17 & 0.45 & 10.54 & - & - \\
\hline 56 & 17.30 & 2,4,6-trimethyl phenol (Mesitol) & 1204 & 95 & - & - & 0.34 & 9.35 & 0.40 & 14.48 \\
\hline 58 & 17.85 & 2-Propyl phenol & 1224 & 93 & - & - & 0.14 & 4.56 & - & - \\
\hline 59 & 18.02 & $p$-Isopropyl phenol ( $p$-Cumenol) & 1230 & 91 & - & - & 0.87 & 3.45 & - & - \\
\hline 60 & 18.13 & 6-Ethyl-o-cresol & 1234 & 91 & - & - & 0.33 & 5.48 & - & - \\
\hline 61 & 18.33 & 4-Ethyl-m-cresol & 1241 & 91 & - & - & 1.48 & 4.00 & 2.09 & 2.35 \\
\hline 62 & 18.45 & 5-Ethyl-m-cresol & 1246 & 94 & - & - & 0.23 & 7.60 & - & - \\
\hline 63 & 18.88 & 4-Propyl phenol & 1262 & 90 & - & - & 0.46 & 4.63 & 0.37 & 2.54 \\
\hline 64 & 18.99 & $\begin{array}{l}\text { 3-Methoxy-1,2-Benzenediol } \\
\text { (3-Methoxy pyrocatechol) }\end{array}$ & 1266 & 96 & 1.95 & 17.19 & 0.98 & 5.46 & - & - \\
\hline 65 & 19.13 & $\begin{array}{l}\text { 2,3,5-trimethyl phenol } \\
\text { (Isopseudo cumenol) }\end{array}$ & 1271 & 94 & - & - & 0.30 & 2.01 & 0.50 & 6.70 \\
\hline 66 & 19.49 & $p$-Ethyl guaiacol & 1284 & 94 & 0.87 & 5.54 & 9.13 & 3.18 & 13.17 & 1.64 \\
\hline 69 & 19.93 & Thymol & 1300 & 91 & - & - & 0.18 & 10.92 & 0.22 & 21.03 \\
\hline 72 & 20.37 & 2,5-Diethyl phenol & 1316 & 76 & - & - & 0.52 & 3.77 & 0.72 & 1.19 \\
\hline 73 & 20.42 & Methyl syringole & 1318 & 90 & - & - & 0.28 & 7.97 & - & - \\
\hline 75 & 20.69 & 4-Ethyl-1,2-dimethoxybenzene & 1328 & 96 & - & - & 0.22 & 8.65 & 0.30 & 13.05 \\
\hline 77 & 21.47 & Pyrogallol 1,3-dimethyl ether (Syringol) & 1356 & 95 & 6.70 & 11.52 & 7.38 & 2.35 & 7.56 & 0.87 \\
\hline 78 & 21.59 & Eugenol & 1361 & 97 & - & - & 0.88 & 4.39 & - & - \\
\hline 79 & 21.68 & 2-Methoxy-4-ethyl-6-Methyl phenol & 1364 & 81 & - & - & 0.31 & 5.71 & - & - \\
\hline 81 & 21.85 & 2-Methoxy-4-propyl phenol (Cerulignol) & 1370 & 91 & - & - & 1.87 & 3.00 & 2.86 & 5.03 \\
\hline 83 & 22.24 & 4-Ethylcatechol & 1385 & 86 & 0.26 & 15.71 & - & - & - & - \\
\hline 84 & 22.56 & 3-Acetylphenol & 1397 & 95 & 0.06 & 14.64 & - & - & - & - \\
\hline 87 & 22.92 & Isoeugenol & 1411 & 95 & - & - & 0.22 & 11.12 & 0.40 & 15.48 \\
\hline 89 & 23.89 & 4-Methyl syringol & 1451 & 93 & 1.05 & 16.97 & 2.99 & 4.81 & 2.49 & 2.81 \\
\hline 97 & 27.63 & 4-ally-2,6-dimethoxy phenol & 1606 & 99 & - & - & 0.67 & 5.25 & 0.54 & 2.23 \\
\hline 98 & 27.79 & 4-Propyl syringol & 1613 & 91 & - & - & 2.34 & 3.92 & 2.06 & 1.80 \\
\hline 103 & 32.44 & 4-Propionyl syringol & 1829 & 80 & - & - & 0.15 & 12.33 & - & - \\
\hline
\end{tabular}


Table 1. Continued

\begin{tabular}{|c|c|c|c|c|c|c|c|c|c|c|}
\hline \multirow{3}{*}{$\begin{array}{l}\text { Peak } \\
\text { No. }\end{array}$} & \multirow{3}{*}{ R.T. } & \multirow{3}{*}{ Compounds } & \multirow{3}{*}{$\mathrm{KI}^{*}$} & \multirow{3}{*}{ Similarity } & \multicolumn{6}{|c|}{ Relative percentage quantities } \\
\hline & & & & & \multicolumn{2}{|c|}{ DA } & \multicolumn{2}{|c|}{ SPME } & \multicolumn{2}{|c|}{ SBSE } \\
\hline & & & & & Area \% & RSD & Area \% & RSD & Area \% & RSD \\
\hline \multicolumn{11}{|l|}{ Ester } \\
\hline 1 & 0.52 & Methyl acetate & & 83 & - & - & 0.41 & 10.99 & 1.10 & 15.59 \\
\hline 2 & 1.18 & Methyl propanoate & & 90 & - & - & - & - & 0.69 & 14.74 \\
\hline 5 & 1.91 & Methyl isobutyrate & & 91 & - & - & - & - & 0.06 & 8.79 \\
\hline 7 & 2.38 & Methyl bytyrate & & 94 & - & - & 0.04 & 15.92 & 0.38 & 16.09 \\
\hline 10 & 5.22 & Methyl isovalerate & & 91 & - & - & - & - & 0.07 & 18.55 \\
\hline 13 & 4.85 & Methyl pentanoate (Methyl valerate) & & 94 & - & - & - & - & 0.12 & 19.44 \\
\hline 14 & 4.98 & Furfuryl methyl ester & & 95 & - & - & - & - & 0.04 & 5.94 \\
\hline 21 & 7.17 & Methyl-4-methylpentanoate & & 87 & - & - & - & - & 0.08 & 26.01 \\
\hline 29 & 10.10 & Methyl-2-furoate & & 95 & - & - & 0.37 & 4.98 & 0.48 & 6.63 \\
\hline 76 & 21.11 & Methyl anisate & 1343 & 70 & - & - & 0.24 & 2.33 & 0.09 & 10.97 \\
\hline 92 & 25.60 & Methyl vanilate & 1522 & 91 & - & - & 0.17 & 23.43 & - & - \\
\hline 94 & 25.94 & Guaiacylacetate & 1536 & 86 & 0.47 & 19.77 & 0.37 & 5.63 & 0.15 & 3.35 \\
\hline 95 & 26.46 & Methyl-p-cumarate & 1557 & 91 & - & - & 0.18 & 10.61 & - & - \\
\hline 102 & 31.33 & Methyl syringate & 1778 & 92 & - & - & 0.34 & 9.98 & 0.17 & 1.65 \\
\hline \multicolumn{11}{|c|}{ Ketone } \\
\hline 6 & 2.04 & 2,3-Pentadione & & 97 & - & - & - & - & 0.03 & 7.48 \\
\hline 9 & 3.38 & 1-Hydroxy-2-butanone & & 72 & 0.37 & 13.35 & 0.06 & 19.68 & 0.07 & 2.09 \\
\hline 11 & 5.42 & 2,4-Dimethyl-3-pentanone & & 90 & - & - & - & - & 0.02 & 12.70 \\
\hline 12 & 5.52 & Cyclopentanone & & 91 & - & - & - & - & 0.19 & 7.98 \\
\hline 16 & 5.31 & 2-Methylcyclopentanone & & 90 & - & - & - & - & 0.10 & 9.75 \\
\hline 22 & 7.62 & 2-Methyl-2-cyclopentenone & & 94 & 0.59 & 29.92 & 0.23 & 6.64 & 0.57 & 11.53 \\
\hline 24 & 7.96 & Butyrolactone & & 90 & 2.45 & 15.81 & 0.29 & 9.48 & 0.10 & 33.41 \\
\hline 25 & 8.21 & 2,5-Hexanedione & & 80 & 0.10 & 5.81 & - & - & - & - \\
\hline 26 & 8.77 & 2,5-Dimethyl-2-cyclopentenone & & 90 & - & - & 0.04 & 6.06 & 0.19 & 12.39 \\
\hline 31 & 10.74 & $\mathrm{t}, \mathrm{t}-3,5$-Heptadien-2-one & & 91 & - & - & 0.09 & 10.84 & - & - \\
\hline 33 & 10.87 & 2,3-Dimethyl-2-cyclopenten-1-one & 1005 & 97 & - & - & 0.14 & 9.61 & 0.37 & 12.64 \\
\hline 34 & 11.21 & 2-Furyl ethyl ketone & 1009 & 78 & - & - & 0.13 & 10.14 & 0.24 & 9.10 \\
\hline 36 & 11.85 & $\begin{array}{l}\text { 2-Hydroxy-3-methyl-2-cyclopenten- } \\
\text { one (Corylone) }\end{array}$ & 1029 & 95 & 1.96 & 13.74 & 0.41 & 16.38 & - & - \\
\hline 40 & 13.04 & Acetophenone & 1067 & 94 & - & - & 0.22 & 14.62 & 0.28 & 16.96 \\
\hline 45 & 14.78 & 3-Ethyl-2-hydroxy-2-cyclopentenone & 1123 & 90 & 0.37 & 13.37 & 0.35 & 7.76 & - & - \\
\hline 48 & 16.04 & 2-Hydroxy acetophenone & 1163 & 93 & - & - & 0.05 & 9.25 & 0.11 & 2.73 \\
\hline 68 & 20.95 & 1-Indanone & 1298 & 98 & - & - & - & - & 0.73 & 7.53 \\
\hline 71 & 20.18 & 2,3-Dihydro-2-methyl-1-Indenone & 1309 & 96 & - & - & 0.22 & 1.84 & 0.25 & 4.88 \\
\hline 74 & 20.57 & 1,3-Dihydro-1-methyl-2-indenone & 1327 & 95 & - & - & - & - & 0.26 & 7.74 \\
\hline 82 & 22.08 & 2,5-Dihydroxypropiophenone & 1379 & 91 & - & - & 0.59 & 2.37 & 0.58 & 2.55 \\
\hline 88 & 23.70 & $p$-Hydroxyacetophenone (piceol) & 1443 & 94 & 0.07 & 35.05 & - & - & - & - \\
\hline \multicolumn{11}{|c|}{ Aldehyde } \\
\hline 15 & 5.16 & 2-Furancarboxaldehyde & & 90 & 2.60 & 9.39 & 3.98 & 5.26 & 2.80 & 9.40 \\
\hline 27 & 9.48 & Benzaldehyde & & 95 & - & - & 0.06 & 3.83 & 0.11 & 16.84 \\
\hline 38 & 12.19 & $\begin{array}{l}\text { 2-Hydroxy benzaldehyde } \\
\text { (Salicyl aldehyde) }\end{array}$ & 1046 & 98 & - & - & - & - & 0.42 & 8.34 \\
\hline
\end{tabular}


Table 1. Continued

\begin{tabular}{|c|c|c|c|c|c|c|c|c|c|c|}
\hline \multirow{3}{*}{$\begin{array}{l}\text { Peak } \\
\text { No. }\end{array}$} & \multirow{3}{*}{ R.T. } & \multirow{3}{*}{ Compounds } & \multirow{3}{*}{$\mathrm{KI}^{*}$} & \multirow{3}{*}{ Similarity } & \multicolumn{6}{|c|}{ Relative percentage quantities } \\
\hline & & & & & \multicolumn{2}{|c|}{ DA } & \multicolumn{2}{|c|}{ SPME } & \multicolumn{2}{|c|}{ SBSE } \\
\hline & & & & & Area \% & RSD & Area $\%$ & RSD & Area $\%$ & RSD \\
\hline 80 & 21.73 & $\begin{array}{l}\text { Benzaldehyde, 4-hydroxy } \\
\text { ( } p \text {-Formyphenol) }\end{array}$ & 1364 & 96 & 0.11 & 21.21 & - & - & - & - \\
\hline 85 & 22.64 & $\begin{array}{l}\text { 3-Methoxy-4-hydroxy benzaldehyde } \\
\text { (Vanillin) }\end{array}$ & 1399 & 90 & 0.14 & 19.20 & 0.17 & 8.19 & - & - \\
\hline 96 & 27.14 & 2-Ethoxy-4-anisaldehyde & 1585 & 83 & - & - & 0.11 & 8.83 & - & - \\
\hline 99 & 28.87 & Syringaldehyde & 1664 & 95 & 0.09 & 26.60 & - & - & 0.05 & 16.19 \\
\hline \multicolumn{11}{|c|}{ Alcohol } \\
\hline 4 & 1.55 & Acetol & & 90 & 3.68 & 10.64 & 0.16 & 25.77 & 0.08 & 18.18 \\
\hline 44 & 14.59 & Maltol & 1117 & 80 & 0.83 & 3.50 & 0.19 & 13.57 & - & - \\
\hline \multicolumn{11}{|c|}{ Pyrazine } \\
\hline 8 & 2.93 & Pyridine & & 91 & 0.30 & 15.56 & 0.01 & 38.90 & 0.02 & 12.29 \\
\hline 17 & 5.33 & 2-Methylpyridine & & 84 & 0.16 & 10.87 & & & - & - \\
\hline 32 & 11.14 & 3-Methoxypyridine & 1004 & 87 & 0.20 & 29.63 & - & - & - & - \\
\hline \multicolumn{11}{|c|}{ Acid } \\
\hline 3 & 1.22 & Acetic acid & & 90 & 38.91 & 9.24 & 3.09 & 18.40 & - & - \\
\hline 101 & 31.31 & Homosyringic acid & 1776 & 81 & 0.44 & 24.71 & - & - & - & - \\
\hline \multicolumn{11}{|c|}{ Furan } \\
\hline 20 & 6.13 & 2-Ethyl furan & & 76 & - & - & - & - & 0.05 & 12.41 \\
\hline 23 & 7.81 & 2-Acetyl furan & & 91 & 0.39 & 7.58 & 0.52 & 9.24 & 0.74 & 8.16 \\
\hline \multirow[t]{2}{*}{37} & 12.15 & 2-Acetyl -5-methylfuran & 1039 & 90 & - & - & 0.10 & 20.21 & - & - \\
\hline & & Other compound & & & & & & & & \\
\hline 18 & 5.79 & 4,5-Dimethyl-1-hexene & & 72 & - & - & - & - & 0.07 & 4.99 \\
\hline 28 & 9.64 & 5-Methyl 2-furfural & & 97 & 0.37 & 10.89 & 0.54 & 8.58 & 0.19 & 16.08 \\
\hline 57 & 17.46 & $\begin{array}{l}\text { 1,4;3,6-Dianhydro-alpha-d-glucopyra- } \\
\text { nose }\end{array}$ & 1210 & 91 & 0.78 & 26.96 & - & - & - & - \\
\hline 67 & 19.84 & 3,4-Dihydroxytoluene & 1295 & 98 & 0.86 & 19.66 & - & - & - & - \\
\hline 70 & 20.01 & 2,5-Dimethoxy toluene & 1309 & 89 & - & - & - & - & 0.06 & 6.07 \\
\hline 86 & 22.81 & $3,4,5$-Trimethoxy toluene & 1406 & 99 & - & - & 0.39 & 2.98 & 0.47 & 5.66 \\
\hline 90 & 24.75 & D-Allose (Hexose) & 1486 & 90 & 1.13 & 38.56 & - & - & - & - \\
\hline 91 & 24.84 & $\begin{array}{l}\text { Acetoguaiacon } \\
\text { (Acetovanilone, Apocynin) }\end{array}$ & 1490 & 89 & 0.21 & 34.22 & 0.23 & 6.51 & 0.15 & 4.17 \\
\hline 93 & 25.84 & 2,3,5-Trimethoxy toluene & 1531 & 95 & 0.60 & 3.90 & 4.31 & 4.36 & 3.81 & 2.33 \\
\hline 100 & 30.45 & Acetosyringone & 1738 & 95 & 0.22 & 23.91 & - & - & 0.05 & 8.44 \\
\hline SUM & & & & & 100 & & 100 & & 100 & \\
\hline
\end{tabular}

*KI: Kovat index

\subsubsection{Gas chromatography-mass spectrometry}

죽초액의 휘발성 향기 성분 분석을 위한 분석방법 의 최적화 및 정량, 정성 분석은 Agilent $7890 \mathrm{GC}$ system/Agilent MD 5973 quadruple mass spectrometer (Agilent Technologies, Middleburg, OH, USA)를 사용하였다. 각 성분의 분리를 위한 $\mathrm{GC}$ column은 HP-5MS (5\%-Phenyl-methylpolysiloxane, $30 \mathrm{~m}$ in length,
$0.25 \mu \mathrm{m}$ i.d., $0.25 \mu \mathrm{m}$ film thickness, Agilent Technologies, Middleburg, OH, USA)를 사용하였다. Carrier gas로는 helium $(99.999 \%)$ 을 사용하여 $1 \mathrm{~mL} / \mathrm{min}$ 의 유 속을 유지하였으며 주입구 온도는 $240{ }^{\circ} \mathrm{C}$ 에서 $10: 1$ 의 split mode를 사용하였다. Column 오븐 초기온도는 40 ${ }^{\circ} \mathrm{C}$ 에서 $3 \mathrm{~min}$ 정치한 후 $5{ }^{\circ} \mathrm{C} / \mathrm{min}$ 속도로 $260{ }^{\circ} \mathrm{C}$ 까지 승온하여 $1 \mathrm{~min}$ 정치하였다. 
MS transfer line, ion source 온도는 각각 $230{ }^{\circ} \mathrm{C}$, $150{ }^{\circ} \mathrm{C}$ 로 유지하였으며 $70 \mathrm{eV}$ 의 electron energy로 full scan mode에서 $35-350 \mathrm{~m} / \mathrm{z}$ 질량 분석 범위로 분 석을 진행하였다. 죽초액 향기성분의 확인동정은 각 성분 표준물질의 mass spectrum과 Wiley 275 mass spectral database (Agilent Technologies, Santa Clara,
CA, USA), 참고 문헌으로 비교 확인하였다.

\subsubsection{Statistical analysis}

분석결과 얻어진 compounds의 측정값은 피크면적 으로부터 얻은 상대적인 면적 백분율(normalized peak area, \%)로 나타내었다.

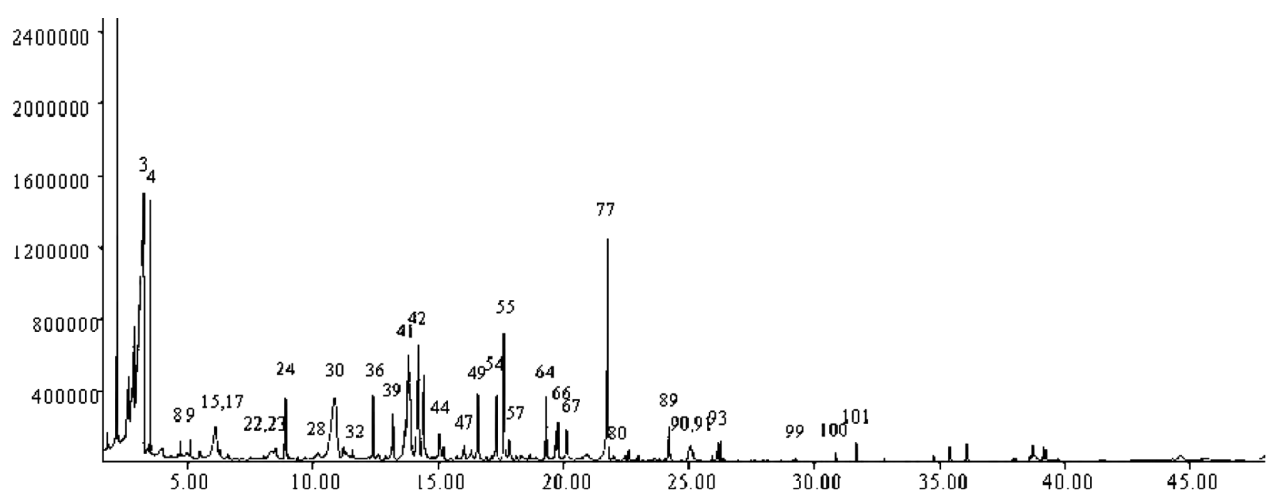

(a)

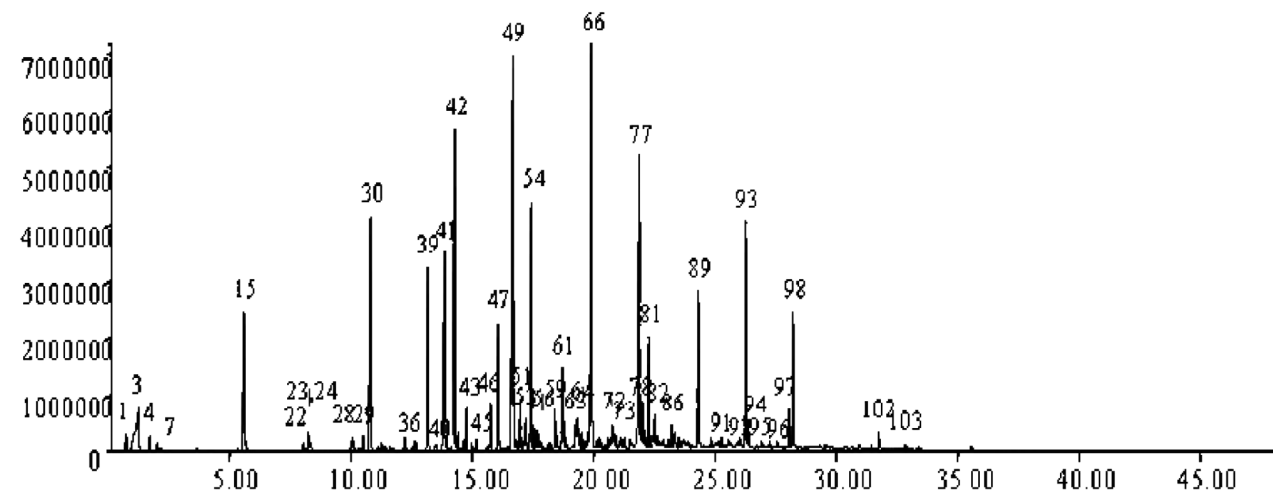

(b)

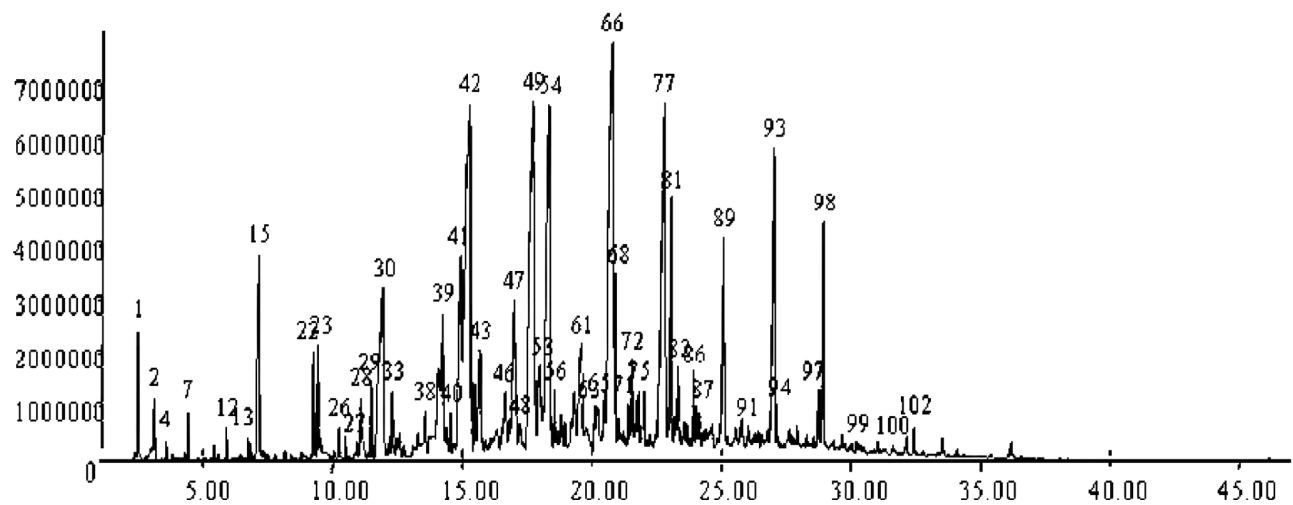

(c)

Fig. 1. TICs of pyroligneous liquor using gas chromatography-mass spectrometry at different sampling methods; (a) Direct analysis, (b) HS-SPME and (c) SBSE. 


\section{3. 결과 및 고찰}

\section{1. $\mathrm{DA}$ 법에 의한 죽초액의 휘발성분}

죽초액의 휘발성성분을 분석하는 방법으로 dynamic headspace sampling 방법은 죽초액 속에 함유된 수분 에 의한 방해로 적절하지 않다. ${ }^{11,12}$ 액체시료인 죽초액 의 휘발성 성분을 분석하는 방법으로 극성이 비교적 낮은 HP-SPME를 사용하는 방법 ${ }^{13,14}$ 과 PDMS가 도포 되어 있는 $\mathrm{SBSE}$ 를 사용할 경우 비교적 효율적으로 휘발성 향기성분을 추출할 수 있다. ${ }^{15,16}$ 따라서 본 연 구에서는 죽초액의 휘발성성분을 직접 분석한 경우 (DA), HP-SPME로 분석한 경우 및 $\mathrm{SBSE}$ 로 분석한 경우를 비교하여 죽초액 중의 휘발성성분을 가장 효 율적으로 분석할 수 있는 방법을 확립하고자 하였다.

Fig. 1(a)는 DA방법으로 죽초액의 휘발성성분을 분 석한 total ion chromatogram (TIC)을 나타내었다. DA 방법으로 죽초액을 분석한 경우는 phenol, 2-methyl phenol, cresol 등 phenol류 15 종이 분리되었고 가장 많 은 성분으로는 phenol과 syringol이 각각 $7.98 \%$ 와 $6.70 \%$ 를 차지하였다. Ester의 경우 guaiacylacetate가 함유되어 있었고 ketone류는 1-hydroxy-2-butanone, butylrolactone 등 7 종류가 검출되었다. Aldehyde의 경우 2-furancarboxaldehyde, 4-hydroxy benzaldehyde 등이 검출되었다. Alcohol류는 acetol과 maltol이 함 유되어있었고 acetic acid가 $38.91 \%$ 로 가장 풍부하게 함유되어 있었다.

\subsection{HS-SPME법에 의한 죽초액의 휘발성분}

HS-SPME법에 의한 죽초액의 휘발성성분 중 검출 된 phenol류는 $\mathrm{DA}$ 법에 분리된 성분과 매우 유사하였 으나 $\mathrm{DA}$ 법으로 검출되지 않은 성분으로는 2,6-xylenol 과 m-ethyl phenol, 3-methyl guaiacol, methyl syringol, eugenol 등이 있었고 총 37 종이 검출되었다. SPME법 으로 검출된 phenol성분 중 많은 함량을 차지하는 성 분으로는 $p$-ethyl phenol, $p$-ethyl guaiacol, o-guaicol, syringol, phenol 등으로 각각 $10.76 \%, 9.13 \%, 7.62 \%$, $7.38 \%$ 및 $7.03 \%$ 가, ester성분으로는 methyl acetate, methyl-2-furoate등 8 종이 검출되었고 그 함량은 다른 성분들에 비하여 비교적 낮았다. Ketone의 경우 DA법 과 비교하여 더 많은 성분이 검출되어 12 종이 검출되 었으나 그 함량은 비교적 적었다. Aldehyde의 경우 2ethoxy-4-anisaldehyde, vanillin, 2-furancarboxaldehyde 가 $8.83 \%, 8.19 \%$ 및 $5.26 \%$ 있었다.

\subsection{SBSE법에 의한 죽초액의 휘발성분}

$\mathrm{SBSE}$ 법에 의한 죽초액의 휘발성성분 중 검출된 phenol류는 총 26 종이었고 $p$-ethyl guaiacol, o-guaiacol, $p$-ethyl phenol, 2-methoxy-p-cresol등이 각각 $13.17 \%$, $11.50 \%, 10.57 \%, 8.12 \%$ 로 많은 양을 차지하였다. Ketone 류의 경우 2,3-pentadione, 2-methyl-2-cyclopentanone, 1indanone 등 총 16 종이 검출되어 $\mathrm{DA}$ 법이나 $\mathrm{SPME}$ 법에 비하여 비교적 많은 성분의 ketone류가 검출되었 다. Aldehyde의 경우 $\mathrm{DA}$ 법과 $\mathrm{SPME}$ 법과 같이 2furancarboxaldehyde가 $2.80 \%$ 로 가장 많은 양을 차지하 였다.

\section{4. 죽초액의 휘발성성분의 특성}

죽초액에 함유되어 있는 휘발성 향기성분은 크게 phenol류, ester류, ketone류, aldehyde류로 분류되며 그 외에 alcohol류, pyrazine류, acid류, furan류의 물질이 미량 포함되어 있다. Direct analysis 방법에서 42 종, SBSE 방법에서 69 종, HS-SPME 방법에서 72 종의 화 합물이 검출되었다. 죽초액의 주요한 화합물인 cresol, guaiacol, $p$-ethyl guaiacol, syringol은 공통적으로 함유되 어 있으며 direct analysis에서는 살충 활성을 나타내는 것으로 알려진 acetic acid가 대략 $40 \%$ 로 주 구성성분 으로 분석되었다. ${ }^{17}$ 반면 DA방법보다 더 많은 화합물 이 검출된 $\mathrm{HP}-\mathrm{SPME}, \mathrm{SBSE}$ 방법에서는 상대적 백분 율에 기인하여 acetic acid의 함량이 적게 나온 것을 보여주며 HS-SPME, SBSE 방법을 이용한 분석에서 는 구성성분의 $80 \%$ 이상이 phenolic compounds로 검 출되는 것을 확인하였다. 이는 $\mathrm{HS}-\mathrm{SPME}$ 와 $\mathrm{SBSE}$ 를 이용하여 추출 하였을때 phenolic compounds의 선택 적 흡착이 가능한 것을 보여준다. Phenolic compounds 는 일반적으로 죽초액 제조시 대나무에 존재하는 리 그닌 성분의 열분해산물에서 기인하며 대부분 기능 활성을 나타내는 것으로 보고되어 있다. ${ }^{18,19}$ Guaiacol, syringol 같은 polyphenolic compounds는 antifungal과 antidermatophyte activity를 가지고 있고, 죽초액의 smoky하고 medicinal한 냄새를 특징짓게 하는 성분 이다. ${ }^{20}$ 또한 죽초액의 alcohol류, ketone류, aldehyde 류 compounds등은 동물이나 식물 등의 조직 내로의 침투성과 흡수성을 용이하게 하는 작용을 한다. ${ }^{21}$ 반 면 죽초액은 포름알데하이드류와 반응하여 타르를 생성하는 phenol, cresol 등의 발암성 유해물질 또한 포함하고 있다. ${ }^{22}$ 일반적으로 타르성분이 높을수록 유 효성분이 차지하는 비율이 낮아지며 죽초액의 품질 
이 저하된다. 따라서 본 연구에서 제시한 추출방법을 이용하면 죽초액의 기능성 성분을 탐색하는데 있어 광범위한 기초자료로 활용할 수 있을 뿐만 아니라 유 해성분의 평가 활용방안으로 모색할 수 있을 것으로 사료된다.

\section{4. 결 론}

DA법, SPME법 및 SBSE법을 이용하여 죽초액의 휘발성성분을 분석하는 방법을 확립하여, 103 종의 화 합물을 확인하였다. 전처리 방법에 따라 검출되는 화 합물에는 차이가 있으며 HS-SPME, SBSE 방법에서 분리가 더 잘 이루어지는 것을 볼 수 있다. 죽초액의 휘발성성분을 분석하는 것은 죽초액을 여러 방면으로 활용하는 데 있어 중요한 의미를 갖는다. 따라서 새롭 게 제시한 분석방법의 활용도가 클 것으로 보이며 또 한 유효한 생리활성 화합물의 발견과 연구방향을 제 시에 기여할 것으로 예상된다.

\section{감사의 글}

본 연구는 담양군의 지원으로 이루어졌으며 이에 감사드립니다.

\section{참고문헌}

1. M. Yoo and H. Chung, Korea J. Food Nutr., 12, 575581 (1999).

2. Y. kimura, S. Suto and M. Tatsuka, Biol. Pharm. Bull., 25, 1026-1029 (2002).

3. J. Panee, In 'Complementary and alternative therapies and the aging population' $1^{\text {st }}$ Ed., p 159, R. R. Watson, Ed., Elsevier, San Diego, 2009.

4. M. Yatagai, G. Unrinin and T. Ohira, Mokuzai Gakkaishi, 34, 184-188 (1988).

5. A. Yasuhara and G. Sugiura, Agric. Bio. Chem., 51,
3049-3060 (1987).

6. M. Yatagai and G. Unrinin, Mokuzai Gakkaishi, 33, 521-529 (1987).

7. M. Yatagai and G. Unrinin, Mokuzai Gakkaishi, 35, 1021-1028 (1989).

8. F. Lee, S. Choi and J. Eun, Korean J. Food Sci. Technol., 34, 719-724 (2002).

9. Y. Kim, S. Kim, K. Kim and Y. Lee, J. Korean Soc. Agric. Chem. Biotechnol., 44, 262-268 (2001).

10. F. Ikergami, T. Sekin and Y. Fuji, Yakugaku Zasshi, 118, 27-30 (1992).

11. J. Ha, Y. Wang, H. Jang, H. Seog and X. Chen, Food Chem., 142, 79-86 (2014).

12. P. Chuenchomrat, A. Assavanig and S. Lertsiri, Science Asia, 34, 199-206 (2008).

13. M. Mestres, O. Busto and J. Guasch, J. Chromatogr. A, 881, 569-581 (2000).

14. T. Barboni, N. Venturini, J. Paolini, J. Desjobert, N. Chiaramonit and J. Costa, Food Chem., 122, 1304-1312 (2010).

15. F. Rodrigues, M. Caldeira and J. S. Camara, Anal. Chim. Acta, 609, 82-104 (2008).

16. D. J. Caven-Quantrill and A. J. Buglass, J. Chromatogr. A, 1218, 875-881 (2000).

17. M. Yatagai, M. Nishimoto, K. Hori, T. Ohira and A. Shibata, J. Wood Sci., 48, 338-342 (2002).

18. T. Ohra-aho, M. Tenkanen and T. Tamminen, J. Anal. Appl. Pyrolysis, 74, 123-128 (2005).

19. A. Fullana, J. A. Contreras, R. C. Striebich and S. S. Sidhu, J. Anal. Appl. Pyrolysis, 74, 315-326 (2005).

20. Y. Akakkabe, Y. Tamura, S. Iwamoto, M. Takabayashi and T. Nyuugaku, Biosci. Biotechnol. Biochem., 70, 2797-2799 (2006).

21. S. Park, 'Bamboo, Bamboo charcoal, Bamboo vinegar', Korea Forest Research Institute, Korea, 2007.

22. S. P. Mun, C. S. Ku, J. Wood Sci., 56, 47-52 (2010). 